\title{
Percutaneous Microwave Coagulation for the Treatment of Small Solitary Focal Nodular Hyperplasia of Liver
}

\author{
Huihong Liang, Xiaodong Song, Liangqi Cao, Shikun Qian, Zili Shao* \\ Department of Hepatobiliary Surgery, The Second Affiliated Hospital of Guangzhou Medical University, \\ Guangzhou, China \\ Email: "zilishao@163.com
}

Received 4 December 2015; accepted 20 August 2016; published 23 August 2016

Copyright (C) 2016 by authors and Scientific Research Publishing Inc.

This work is licensed under the Creative Commons Attribution International License (CC BY).

http://creativecommons.org/licenses/by/4.0/

(c) (i) Open Access

\begin{abstract}
Background: Whether percutaneous microwave coagulation (PMC) is safe and effective for the treatment of symptomatic focal nodular hyperplasia (FNH) of the liver remains unknown. Methods: Between January 2006 and September 2015, sixteen patients with solitary symptomatic FNHs in the liver (the largest diameter less than $5 \mathrm{~cm}$ ) were treated by PMC. The safty and effectiveness were analyzed. Results: There were 4 males and 12 females. All these patients suffered from upper abdominal pain. The FNHs ranged in size from $3.2 \mathrm{~cm}$ to $5.0 \mathrm{~cm}(3.9 \mathrm{~cm} \pm 0.12$ $\mathrm{cm}$ ). All the PMC procedures were performed successfully. All 16 patients had symptomatic improvement after the treatment with no procedure-related morbidity or mortality. Among 16 patients, $15(93.8 \%)$ patients with FNHs were assessed to be ablated completely by CT examination performed within four weeks after PMC treatment. One patient failed to follow up regularly, but showed up 2 years and 7 months later for suffering upper abdominal pain again with original FNH enlargement, and the patient received surgical resection of the FNH and achieved asymptomatic aftermath. Conclusion: PMC is safe and effectiveness for symptomatic liver FNHs. PMC should be considered to be an alternative modality for those solitary FNHs with less than $5 \mathrm{~cm}$ in diameter.
\end{abstract}

Keywords

Focal Nodual Hyperplasia, Percutaneous Microwave Coagulation, Liver

\section{Introduction}

Focal nodular hyperplasia (FHN) is the second most common benign liver tumor after liver haemangiomas [1]. *Corresponding author.

How to cite this paper: Liang, H.H., Song, X.D., Cao, L.Q., Qian, S.K. and Shao, Z.L. (2016) Percutaneous Microwave Coagulation for the Treatment of Small Solitary Focal Nodular Hyperplasia of Liver. Open Journal of Gastroenterology, 6, $205-213$. http://dx.doi.org/10.4236/ojgas.2016.68026 
An incident of $0.31 \%$ was reported in a large autopsy study of 2270 cadaveric specimens [1]. Generally, FNH is thought to arise as a hyperplastic lesion in response to a preexisting arterial malformation [1]. Considering the indolent natural history of FNH, the rare chance of acute complications, and the fact that there is no potential for malignant change, patients with asymptomatic FNH should be treated conservatively [2]. Surgery or interventional management should be considered only for patients with persistent symptom attributable to FNH, or those with atypical lesions that have increased in size or changed their imaging characteristics that malignant process cannot be confidently ruled out [2].

Elective surgery resection of the FNH has been thought to be the optimal treatment for symptomatic FNH because of its effective for symptom reduction, and also for it can confirm the diagnosis by histopathology for those uncertain FNH [3]-[6]. Nevertheless, surgery resection has the side effect of great trauma for patients and a certain complication rate. Twenty percent of the perioperative complication rate was reported, which include chest infection, subhepatic abscess, and wound infection [7].

In the last two decades, image-guide percutaneous thermal ablation technique has emerged as a routinely treatment for liver tumor. The comparable overall survival rates and the advantage of mini-invasive compared with hepatectomy for small hepatocellular carcinoma ( $5 \mathrm{~cm}$ or less) have been well documented for this technique [8] [9]. As one of the most common used percutaneous thermal ablation technique, percutaneous microwave coagulation (PMC) has been widely used to treat liver malignant [10] [11]. Microwave coagulation system consists of a generator and a monopolar electrode connected to the generator that is introduced to the lesion through an access needle, applying a coaxial technique [12]. The devices use frequencies higher than $900 \mathrm{MHz}$ (mostly $915 \mathrm{MHz}$ and $2.54 \mathrm{GHz}$ ). PMC uses electromagnetic energy to create a rapid and homogeneous heating of tissue and subsequently coagulation necrosis [12] [13]. With the recently developed PMC technique, such as the application of an internally-cooled antenna, larger ablation volume can be achieved with fewer complications, such as skin burn [14] [15]. To the best of our knowledge, there has been no report published in the medical literature using PMC to treat symptomatic FNH. The aim of this study is to initially investigate the therapeutic effect of PMC for solitary small FNH (5 cm or less).

\section{Patients and Methods}

\subsection{Patient Selection}

This prospective study was approved by the ethics committee of the second affiliated hospital of Guangzhou Medical University. Between January 2006 and September 2015, sixteen patients with FNH received PMC. We selected those 16 patients for PMC in this study using the following criteria (selection process see Figure 1).

\subsubsection{Inclusion}

1. The diagnosis of liver FNH was confirmed by histopathology obtained by ultrasound-guided (US) biopsy before PMC.

2. Solitary FNH with the largest diameter less than $5 \mathrm{~cm}$.

3. Patients suffer from symptoms attributable to FNH.

4. FNH lesions visible at ultrasonography (US), with an acceptable and safe path between the lesion and the skin seen on the US scan.

5. No severe liver dysfunction (Child-Pugh class C), or significant coagulopathy (prothrombin activity $<40 \%$, platelet count $<40 \times 10^{9} / \mathrm{mm}^{3}$ ).

\subsubsection{Exclusion}

1. The diagnosis of liver FNH was not confirmed by histology, or those refused to have biopsy.

2. Asymptomatic FNH; or those with non-specific symptoms; or with symptoms attributable to other reasons.

3. Multi-FNHs or the largest diameter of FNH larger than $5 \mathrm{~cm}$.

4. Those patients with FNH were considered unsuitable for percutaneous thermal ablation due to anatomic reason, or those refused to receive PMC.

5. Acute or active inflammatory and infectious lesions in any organ.

6. Acute or severe chronic renal failure, pulmonary insufficiency or heart dysfunction.

All 16 patients with symptomatic FNH were initially detected by transabdominal ultrasound (US) examination. Most of those FNHs appeared to be well-demarcated homogeneous hypo- or isoechoic lesion on US im- 
ages. A multi-phase contrast-enhanced computed tomography (CT) scan was carried out to make a more confident diagnosis. Typical finding on CT scan for FNH was regarded as the followings: well-circumscribed lesion with iso- or hypodense on non-contrast phase; homogeneous intense enhancement throughout the lesion in the arterial phase and iso-or hypodense in the portal venous phase, sometimes followed by gradual enhancement of the central scar on delays scans. For those patients with suspect FNH accompanied with symptoms, electrocardiogram and chest X-ray examination were routinely carried out to identify whether those symptoms were attributable to at cardiac or thoracic disease. Upper gastrointestinal barium meal or gastroscope was undergone to rule out chronic gastritis or peptic ulcer, ultrasound examination to rule out urinary disease or biliary disease. All those examination help to make a more confident judgment that the symptoms the patients suffered were attributable to the suspect FNH. Biopsy followed by PMC would be recommended for those symptomatic solitary FNH less than $5 \mathrm{~cm}$ in diameter.

\subsection{Microwave System}

The microwave system (MTC-3CA, Kangyou Medical, China) consists of a microwave generator which can produce $0 \mathrm{~W}-100 \mathrm{~W}$ of power at $2450 \mathrm{MHz}$, a flexible coaxial cable, a water-pumping machine and an internally-cooled needle antenna $(2.0 \mathrm{~mm}$ in diameter and $18 \mathrm{~cm}$ in length). The needle shaft has a Teflon coating to prevent tissue adhesion. Inside the shaft, there are dual channels through which distilled water under room temperature is pumped by a peristaltic pump. The flow rate of the distilled water was $60 \mathrm{ml} / \mathrm{min}$ that can

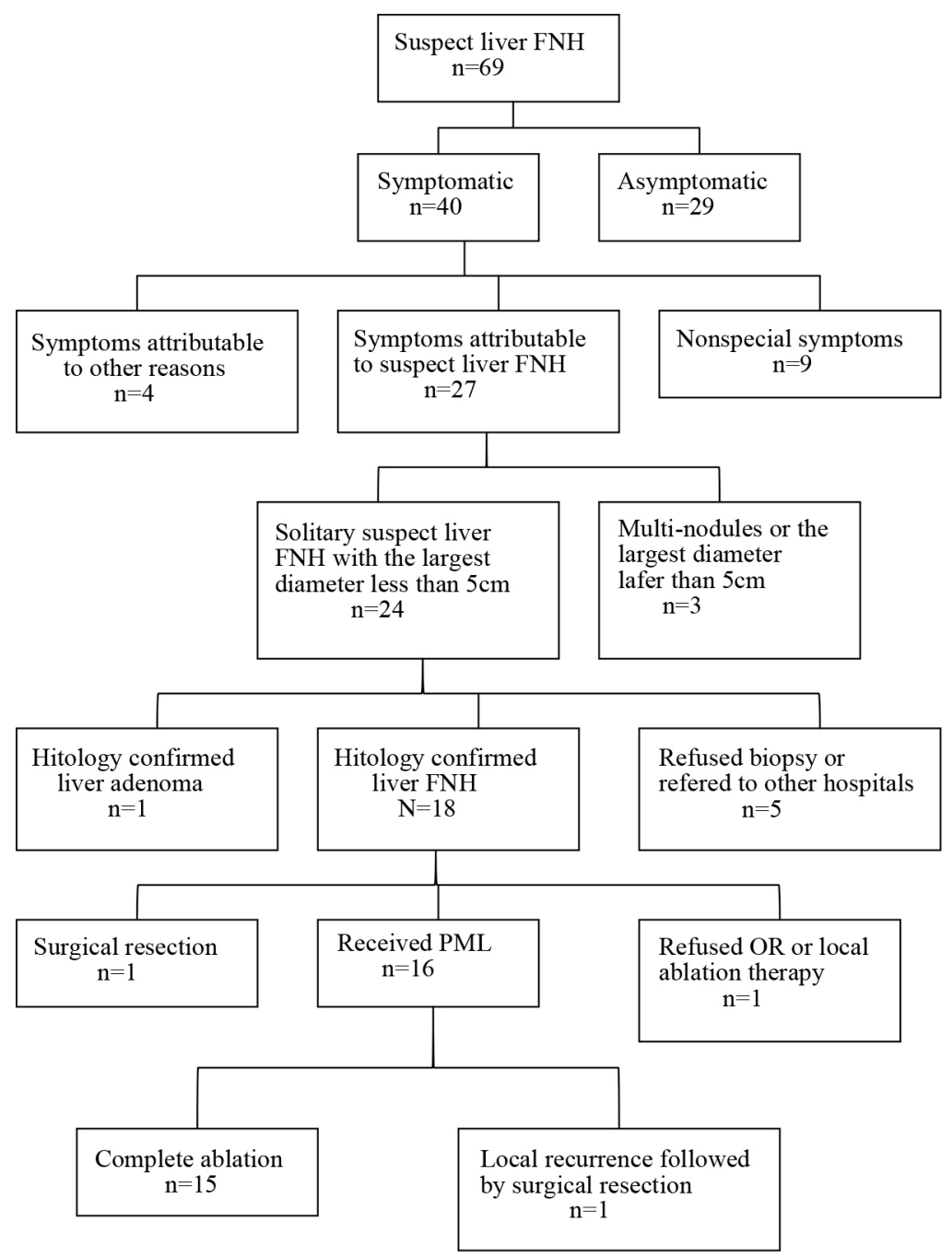

Figure 1. Flow diagram showing the selection process of the patients. 
effectively prevent overheating of the shaft. The radiating segment of $3 \mathrm{~mm}$ is embedded on the shaft, $12.5 \mathrm{~mm}$ away from the tip.

\subsection{PMC Procedure}

All patients underwent PMC at the second affiliated hospital of Guangzhou Medical University. All patients were informed the details and potential complications of the PMC procedure and signed the informed consent form. All PMC procedures were performed with real-time US guidance (EUB-2000, Hitachi Medical Systems, Tokyo, Japan) by a single interventional radiologist (H.H.L), who had 6 years of experience in interventional therapy at the start of the study in January 2006. The patients were placed in the supine position. A local anesthetic, 1\% lidocaine (Harvest pharmaceutical Co, LTD. Shanghai, China), was injected from the insertion point on the skin to the peritoneum, along the planned puncture track. The skin was incised with a small lancet, and the internally-cooled needle antenna was advanced to the chosen area. A detailed protocol was worked out for each patient on an individual basis before treatment, which included the placement of the antennas, power output setting, emission time and appropriate approach. In general, for tumors less than $3.0 \mathrm{~cm}$ in diameter, a single antenna was used, for tumors $3.0 \mathrm{~cm}$ or larger, multiple overlapping antenna deposition described by Chen et al was used [16]. An output setting of $60 \mathrm{~W}$ for 300 seconds was routinely used during each ablation session. When all sessions completed, needle track ablation was routinely carried out to prevent bleeding. Conscious analgesic sedation with intravenous fentanyl citrate and droperidol was induced before the procedure.

\subsection{Follow-Up and Therapeutic Effect Evaluation}

Generally, a dual-phase contrast-enhanced spiral computed tomography (CT) will be carried out four weeks after PMC. Those completely ablated zones appeared as non-enhancing areas of low attenuation at contrast-enhanced CT images which represented coagulation necrosis. Incomplete ablation was considered to be present on the first CT assessment at four weeks after treatment if enhancement areas were seen within the index FNH at either the arterial or the portal venous phase. Repeat PMC or other treatment options which include surgery resection will be offered according to the patient symptomatic improvement or the FNH enlargement.

Complications were stratified according to the Clavien classification of postoperative surgical complications [17]. Major complications were defined as complications with Clavien classification Grade II or higher, which resulted in an unplanned increase in the level of medical care, prolonged hospitalization, permanent adverse sequelae, or death.

\section{Results}

There were 4 males and 12 females. All these patients suffered from upper abdominal pain. Their ages ranged from 20 to 45 years $(34.4 \pm 1.67$ years). The tumors ranged in size from $3.2 \mathrm{~cm}$ to $5.0 \mathrm{~cm}(3.9 \mathrm{~cm} \pm 0.12 \mathrm{~cm})$ (Table 1). All these sixteen patients have normal hepatic function of Child-Pugh class A, and normal of AFP levels $(<25 \mathrm{ng} / \mathrm{ml})$, and no history of hepatitis.

\subsection{Technical Success and Safety}

All the procedures were performed successfully. There was no major or early complication, periprocedural death, or delayed complication in this study. Moderate fever $\left(<39^{\circ} \mathrm{C}\right)$ developed in only one patient and the fever resolved three days after the ablation. Minor insertion point pain happened in all patients and dismissed in one to six days after PMC without medication release.

\subsection{Treatment Effectiveness}

Among 16 patients, 15 (93.8\%) patients with FNHs were assessed to be ablated completely by CT examination performed within four weeks after PMC treatment. These completely ablated zones appeared as non-enhancing areas of low attenuation at contrast-enhanced CT images which represented coagulation necrosis (Figure 2). They involuted gradually over time. One patient failed to follow up regularly, but showed up 2 years and 7 months later for suffering upper abdominal pain again. A larger suspect $F N H$ lesion with the diameter of $6.1 \mathrm{~cm}$ was detected at the original site of the left lobe of the liver on CT scan (Figure 3). A non-enhancing area at all 
Table 1. Demographic data, FNH characteristics and treatment.

\begin{tabular}{|c|c|c|c|c|c|c|c|}
\hline $\mathrm{NO}$ & Age/Sex & $\begin{array}{l}\text { Size } \\
(\mathrm{cm})\end{array}$ & Site $^{*}$ & $\begin{array}{l}\text { No. of } \\
\text { session }\end{array}$ & $\begin{array}{c}\text { Ablation } \\
\text { Effectiveness }\end{array}$ & $\begin{array}{l}\text { Symptomatic } \\
\text { improvement }\end{array}$ & $\begin{array}{l}\text { Surgery } \\
\text { resection }\end{array}$ \\
\hline 1 & $45 / F$ & 3.8 & VII & 2 & complete & Yes & No \\
\hline 2 & $40 / \mathrm{M}$ & 4.0 & VI & 4 & complete & Yes & No \\
\hline 3 & $32 / \mathrm{F}$ & 4.2 & VII & 3 & complete & Yes & No \\
\hline 4 & $27 / F$ & 4.5 & II, III & 3 & $\mathrm{NA}^{* *}$ & Yes & Yes \\
\hline 5 & $36 / \mathrm{M}$ & 4.0 & IV & 4 & complete & Yes & No \\
\hline 6 & $43 / F$ & 3.8 & VII, VIII & 4 & complete & Yes & No \\
\hline 7 & $38 / \mathrm{F}$ & 3.5 & $\mathrm{~V}$ & 3 & complete & Yes & No \\
\hline 8 & $40 / F$ & 3.5 & V & 3 & complete & Yes & No \\
\hline 9 & $37 / \mathrm{F}$ & 3.9 & $\mathrm{~V}, \mathrm{VI}$ & 3 & complete & Yes & No \\
\hline 10 & $25 / \mathrm{M}$ & 3.2 & VII & 2 & complete & Yes & No \\
\hline 11 & $30 / \mathrm{F}$ & 5.0 & VII & 5 & complete & Yes & No \\
\hline 12 & $38 / \mathrm{F}$ & 4.2 & $\mathrm{~V}, \mathrm{VI}$ & 3 & complete & Yes & No \\
\hline 13 & $29 / \mathrm{M}$ & 4.5 & IV & 2 & complete & Yes & No \\
\hline 14 & $20 / \mathrm{F}$ & 3.5 & II,III & 2 & complete & Yes & No \\
\hline 15 & $32 / \mathrm{F}$ & 3.5 & $\mathrm{~V}, \mathrm{VI}$ & 3 & complete & Yes & No \\
\hline 16 & $36 / \mathrm{F}$ & 4.0 & VI & 3 & complete & Yes & No \\
\hline
\end{tabular}

*Couinaud segmental classification; ${ }^{* *}$ The patient had complete symptomatic improvement after the treatment of PMC, but failed to follow up regularly and the ablation effectiveness could not be determined. She showed up 2 years and 7 months later for suffering upper abdominal pain again. A larger suspect FNH lesion with the diameter of $6.1 \mathrm{~cm}$ was detected at the original site of the left lobe of the liver and received surgical resection.

CT phase was within the FHN. We cannot determine whether it is a new FNH or an incomplete ablated FNH because the patient has no comparable CT images early after PMC. Also as the lesion show character of enlargement compared with the original FNH, surgical resection was advised to the patient and the lesion was removed. FNH was confirmed by pathology again and the non-enhancing area was necrosis zone.

\section{Discussion}

Percutaneous thermal ablation served as the treatment for FNH was firstly introduced by Hedayati P and his co-worker in 2010 [18]. The authors reported a 21 years old woman who was taking oral contraceptives for severe dysmenorrheal suffered right upper quadrant pain due to the liver FNH. This patient had a solitary $2.2 \mathrm{~cm}$ FNH located in the Couinaud segments VII and VIII. CT-directed percutaneous radiofrequency ablation was successfully performed with no morbidity or mortality. Symptomatic improvement was achieved after the RFA and maintained for at least 2 years which allowed the patient to receive more aggressive management of other discomfort. The study indicated that except for surgical resection, percutaneous thermal ablation offers more options for this set of patients with symptomatic FNH with the advantage of less invasive.

This study showed that all sixteen patients had symptomatic improvement after the treatment with no 


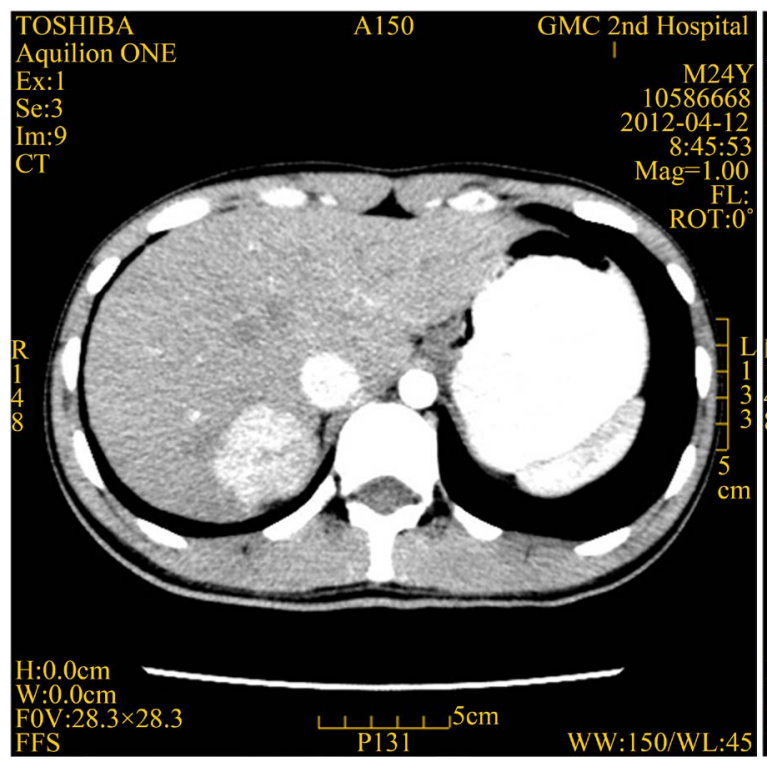

(a)

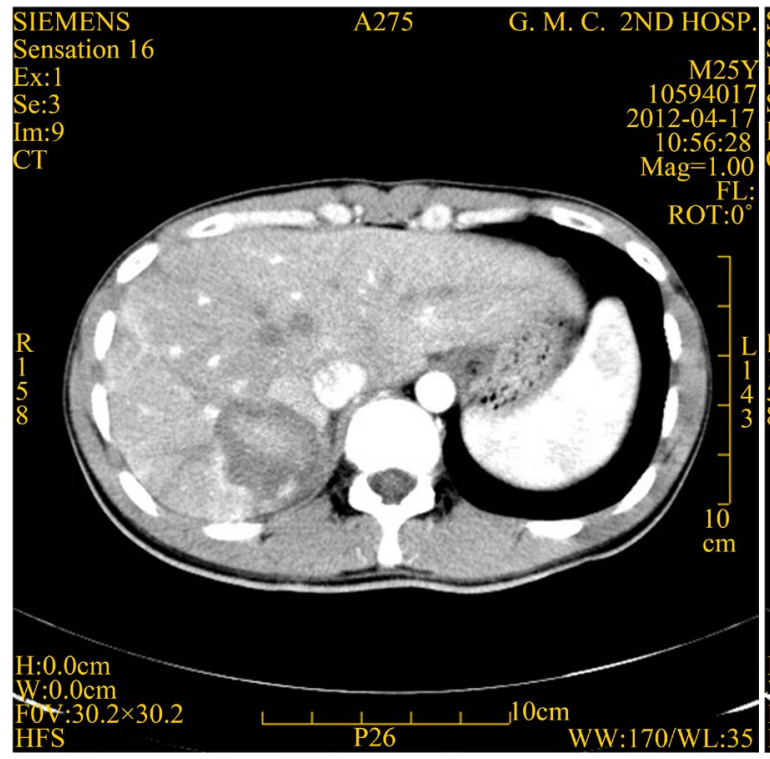

(c)

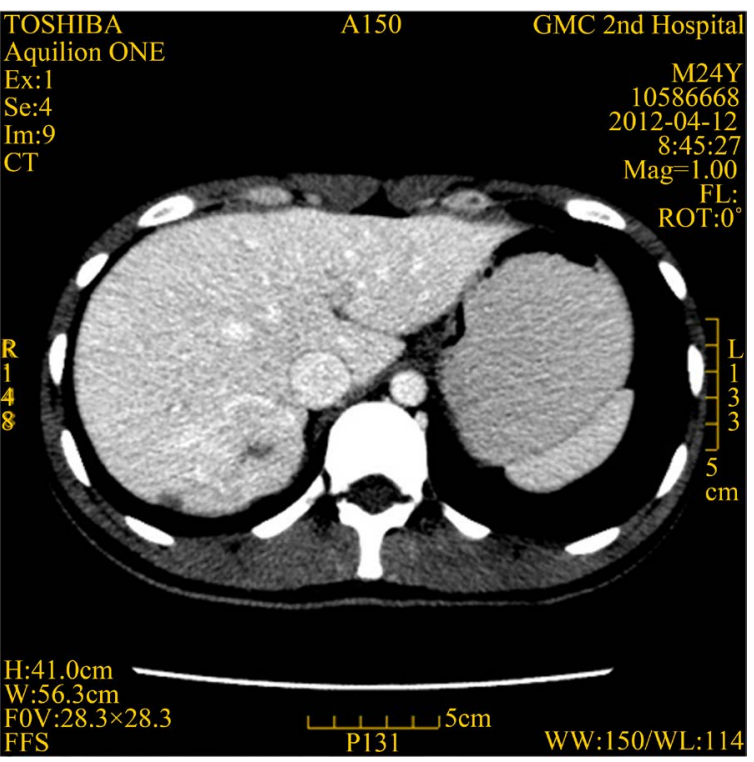

(b)

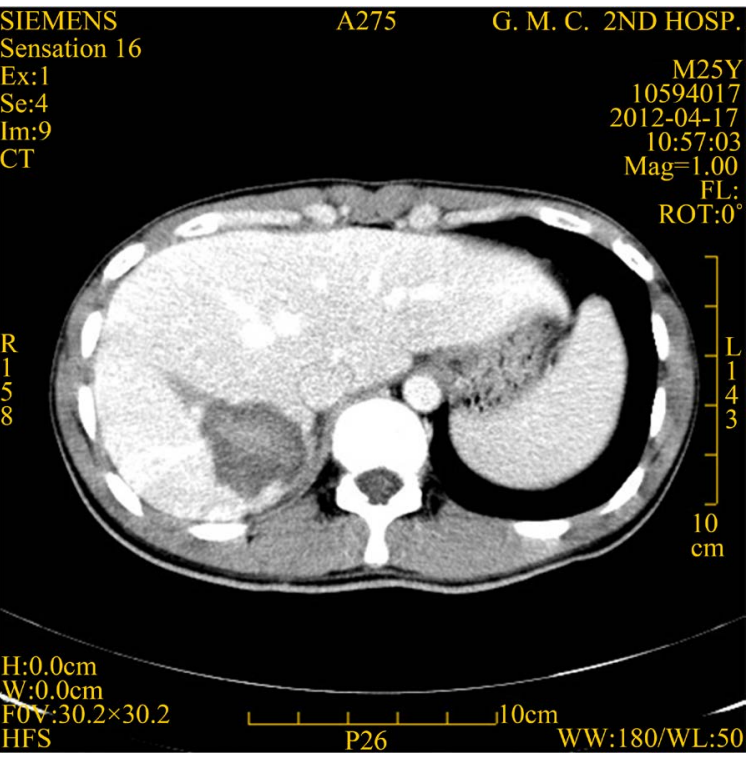

(d)

Figure 2. Complete thermal ablation of FNH treated by PMC. Graphs showing a 25 years old young man with a mass located in the Couinaud segment VII of the liver. The patient suffered from upper abdominal pain. Before PMC, abdominal CT scan obtained in the arterial phase demonstrated a solitary $3.2 \mathrm{~cm}$ homogeneous hypervascular mass in the liver (a), and a central stellate scar within the mass in portal phase (b). After PMC, no residual enhancement in the ablation index FNH site both in arterial phase (c) and portal phase (d), which meant a complete ablation, was achieved. The patient was asymptomatic aftermath.

procedure-related morbidity or mortality. Safety and effectiveness of PMC in the treatment of FNH were demonstrated in this study. Base in the experience achieved by this study, we assume that local thermal ablation serves as the preferable treatment for symptomatic FNHs is credited by the followings: Firstly, as some authors has reported that most FNH nodules are usually solitary [1] [19], and with the diameter range between $40 \mathrm{~mm}$ to $50 \mathrm{~mm}$ [20] [21], which is the best indication for percutaneous thermal ablation [8] [9]. With the latest technique, most ablation electrode or antenna can create a necrosis zone at about $5 \mathrm{~cm}$ in diameter in a single treatment session which is large enough to cover this set of benign liver tumor. Secondly, as we all know, local tumor progression after treatment for malignant tumor is a major concern for thermal ablation [8] [9]. Most local 


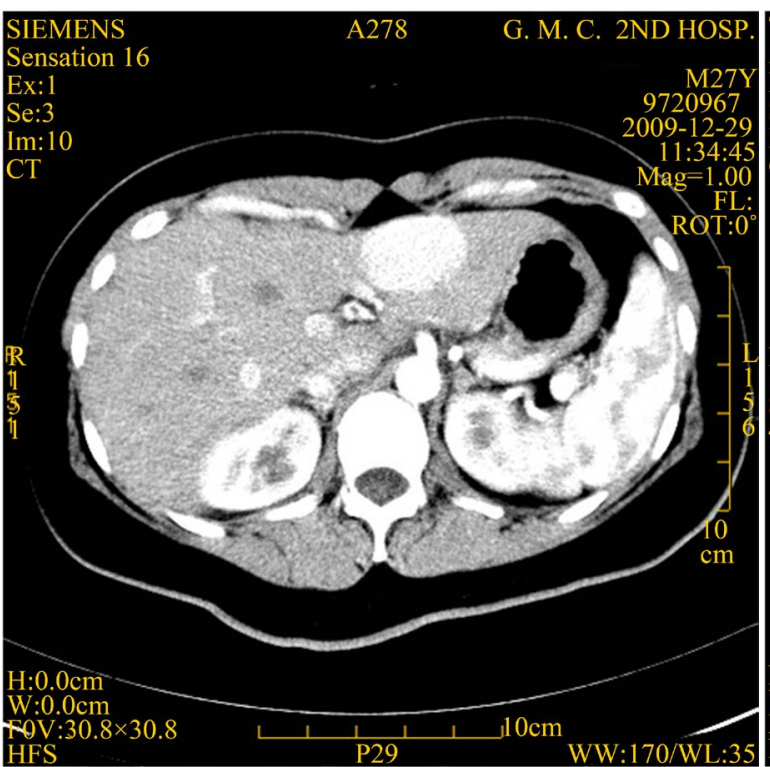

(a)

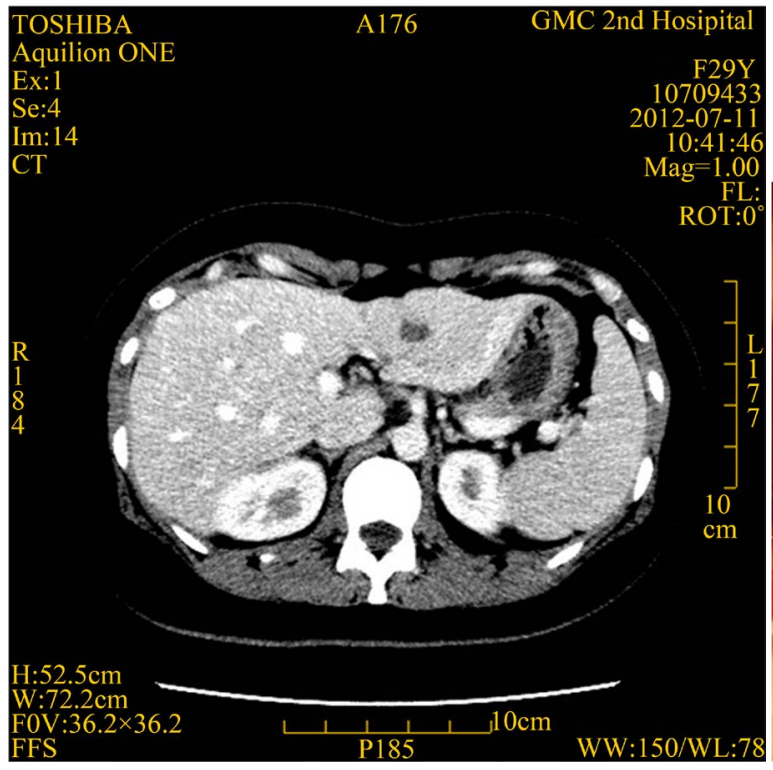

(c)

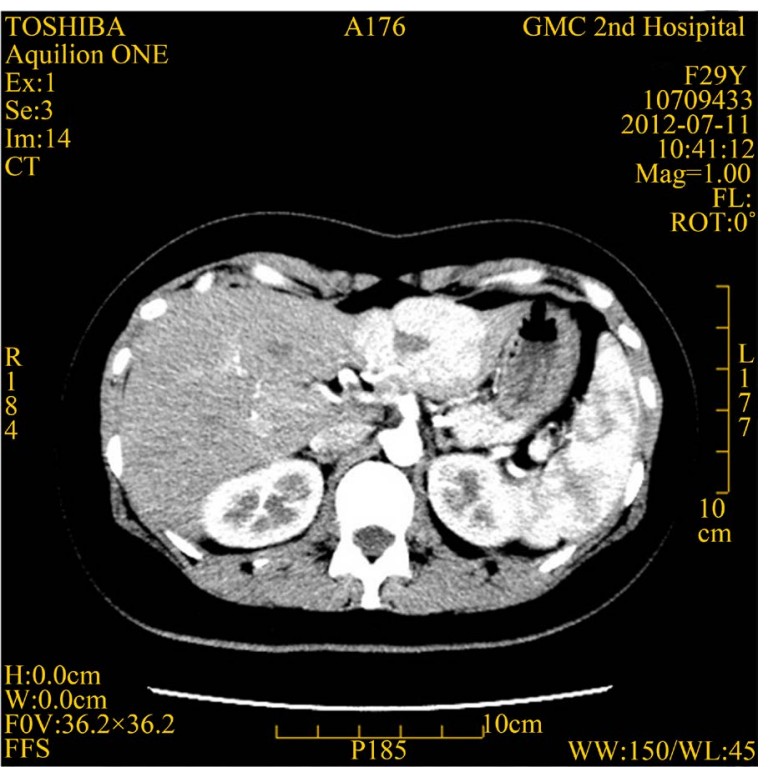

(b)

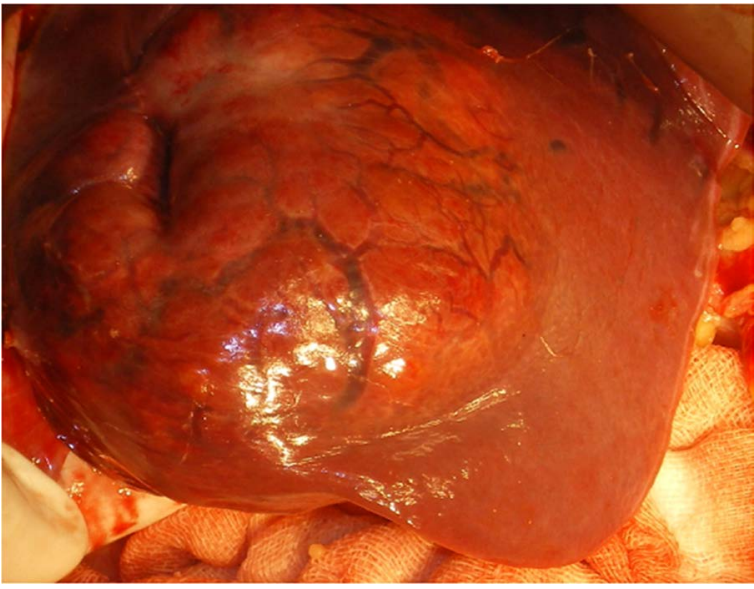

(d)

Figure 3. Surgical resection of FNH resulted in unsuccessfully PMC. Graphs showing a 27 years old young woman with a mass located in the Couinaud segment II and III of the liver. The patient suffered from upper abdominal pain. Before PMC, abdominal CT scan obtained in the arterial phase demonstrated a solitary $4.5 \mathrm{~cm}$ homogeneous hypervascular mass in the liver (a). The patient failed to follow up regularly after the PMC and showed up 2 years and 7 months later for suffering upper abdominal pain again. A larger suspect FNH lesion with the diameter of $6.1 \mathrm{~cm}$ was detected at the original site of the left lobe of the liver. The lesion appeared to be homogeneous hypervascular in arterial phase (b) and slightly hypodense compared to adjacent liver parenchyma in portal phase (c). A non-enhancing area at all CT phase within the lesion (b, c) was assumed to be the necrosis zone resulted in previous PMC. The patient received surgical resection. Hypervascular could be seen in the surface of the mass (d). Diagnosis of FNH was confirmed by pathology and the patient was asymptomatic aftermath.

tumor progression is caused by incomplete ablation. In order to achieve complete ablation, ablation zone is required to be large enough to cover the index malignant tumor with a safe margin of at least $0.5 \mathrm{~cm}$. FNH is a benign tumor with rare potential malignant change [2]. It is not necessary to achieve a large cecrosis zone with such a safe margin, which means thermal ablation is more feasible technically for treating FNH than malignant 
tumor. Thirdly, compared with partial hepatectomy, PMC has the advantage of being less invasive. The patients can recover sooner and better cost-effective treatment is achieved.

As is indicated in this study, most solitary FNH less than $5 \mathrm{~cm}$ can be completely ablated by PMC, but for those incompletely ablated FNHs, a repeat PMC is a reasonable choice but not necessary. It depends on the symptomatic improvement. If the patients is asymptomatic after the previous PMC, and the diagnosis of FNH is confirmed by pathology achieved by biopsy before PMC, it is not necessary to perform a repeat PMC for the residual FNHs. Regular follow up is preferred. But for those with symptom due to the enlargement of the FNH during the follow up, especially when malignant transformation cannot be completely excluded in radiologic images, repeat PMC or surgical resection should not be hesitant.

This study has the limitation of very small study population. This is because of the relatively low incidence of the FNH and most FNH is asymptomatic which does not require medical intervention. But even with such a small study sample, the effectiveness of the PMC was fully demonstrated. Owning to the advantage of being less invasive, PMC should be considered to be a modality for symptomatic FNH, especially for those FNHs less than $5 \mathrm{~cm}$.

\section{Conclusion}

PMC is safe and effectiveness for symptomatic liver FNHs. PMC should be considered to be an alternative modality for those solitary FNHs with less than $5 \mathrm{~cm}$ in diameter.

\section{Acknowledgements}

This work was supported by Pearl River S\&T Nova Program of Guangzhou (2011J2200004) and the grant of Sciences and Technology Committee of Guangdong Province (2011B031800072 and 2013B021800300), China.

\section{Authors' Contributions}

Guarantors of integrity of entire study, Hui-Hong Liang and Zi-Li Shao; study concepts, study design, data acquisition and analysis/interpretation, manuscript drafting, all authors.

\section{References}

[1] Wanless, I.R., Mawdsley, C. and Adams, R. (1985) On the Pathogenesis of Focal Nodular Hyperplasia of the Liver. Hepatology, 5, 1194-1200. http://dx.doi.org/10.1002/hep.1840050622

[2] Nahm, C.B., Ng, K., Lockie, P., Samra, J.S. and Hugh, T.J. (2011) Focal Nodular Hyperplasia: A Review of Myths and Truths. Journal of Gastrointestinal Surgery, 15, 2275-2283. http://dx.doi.org/10.1007/s11605-011-1680-x

[3] Li, A.J., Zhou, W.P. and Wu, M.C. (2006) Diagnosis and Treatment of Hepatic Focal Nodular Hyperplasia: Report of 114 Cases. Chinese Journal of Surgery, 44, 321-323.

[4] Perrakis, A., Demir, R., Muller, V., et al. (2012) Management of the Focal Nodular Hyperplasia of the Liver: Evaluation of the Surgical Treatment Comparing with Observation Only. The American Journal of Surgery, 204, 689-696. http://dx.doi.org/10.1016/j.amjsurg.2012.02.006

[5] Huang, J., Li, B.K., Yuan, Y.F., et al. (2005) Clinical Analysis of 38 Cases of Hepatic Focal Nodular Hyperplasia and Literature Review. Chinese Journal of Cancer, 24, 1241-1245.

[6] Navarro, A.P., Gomez, D., Lamb, C.M., Brooks, A. and Cameron, I.C. (2013) Focal Nodular Hyperplasia: A Review of Current Indications for and Outcomes of Hepatic Resection. HPB (Oxford), 16, 503-511. http://dx.doi.org/10.1111/hpb.12169

[7] Bonney, G.K., Gomez, D., Al-Mukhtar, A., Toogood, G.J., Lodge, J.P. and Prasad, R. (2007) Indication for Treatment and Long-Term Outcome of Focal Nodular Hyperplasia. HPB (Oxford), 9, 368-372. http://dx.doi.org/10.1080/13651820701504173

[8] Chen, M.S., Li, J.Q., Zheng, Y., et al. (2006) A Prospective Randomized Trial Comparing Percutaneous Local Ablative Therapy and Partial Hepatectomy for Small Hepatocellular Carcinoma. Annals of Surgery, 243, 321-328. http://dx.doi.org/10.1097/01.sla.0000201480.65519.b8

[9] Liang, H.H., Chen, M.S., Peng, Z.W., et al. (2008) Percutaneous Radiofrequency Ablation versus Repeat Hepatectomy for Recurrent Hepatocellular Carcinoma: A Retrospective Study. Annals of Surgical Oncology, 15, 3484-3493. http://dx.doi.org/10.1245/s10434-008-0076-y 
[10] Liang, P., Dong, B., Yu, X., et al. (2005) Sonography-Guided Percutaneous Microwave Ablation of High-Grade Dysplastic Nodules in Cirrhotic Liver. American Journal of Roentgenology, 184, 1657-1660. http://dx.doi.org/10.2214/ajr.184.5.01841657

[11] Liang, P., Wang, Y., Yu, X. and Dong, B. (2009) Malignant Liver Tumors: Treatment with Percutaneous Microwave Ablation-Complications among Cohort of 1136 Patients. Radiology, 251, 933-940. http://dx.doi.org/10.1148/radiol.2513081740

[12] Poulou, L.S., Botsa, E., Thanou, I., Ziakas, P.D. and Thanos, L. (2015) Percutaneous Microwave Ablation vs Radiofrequency Ablation in the Treatment of Hepatocellular Carcinoma. World Journal of Hepatology, 7, 1054-1063. http://dx.doi.org/10.4254/wjh.v7.i8.1054

[13] Gillams, A.R. (2005) Image Guided Tumour Ablation. Cancer Imaging, 5, 103-109.

[14] Wang, Y., Sun, Y., Feng, L., Gao, Y., Ni, X. and Liang, P. (2008) Internally Cooled Antenna for Microwave Ablation: Results in ex Vivo and in Vivo Porcine Livers. European Journal of Radiology, 67, 357-361. http://dx.doi.org/10.1016/j.ejrad.2007.07.015

[15] Yu, J., Liang, P., Yu, X., Liu, F., Chen, L. and Wang, Y. (2011) A Comparison of Microwave Ablation and Bipolar Radiofrequency Ablation Both with an Internally Cooled Probe: Results in ex Vivo and in Vivo Porcine Livers. European Journal of Radiology, 79, 124-130. http://dx.doi.org/10.1016/j.ejrad.2009.12.009

[16] Chen, M.H., Yang, W., Yan, K., et al. (2004) Large Liver Tumors: Protocol for Radiofrequency Ablation and Its Clinical Application in 110 Patients-Mathematic Model, Overlapping Mode, and Electrode Placement Process. Radiology, 232, 260-271. http://dx.doi.org/10.1148/radiol.2321030821

[17] Dindo, D., Demartines, N. and Clavien, P.A. (2004) Classification of Surgical Complications: A New Proposal with Evaluation in a Cohort of 6336 Patients and Results of a Survey. Annals of Surgery, 240, 205-213. http://dx.doi.org/10.1097/01.sla.0000133083.54934.ae

[18] Hedayati, P., Van Sonnenberg, E., Shamos, R., Gillespie, T. and McMullen, W. (2010) Treatment of Symptomatic Focal Nodular Hyperplasia with Percutaneous Radiofrequency Ablation. Journal of Vascular and Interventional Radiology, 21, 582-585. http://dx.doi.org/10.1016/j.jvir.2009.12.385

[19] Nguyen, B.N., Flejou, J.F., Terris, B., Belghiti, J. and Degott, C. (1999) Focal Nodular Hyperplasia of the Liver: A Comprehensive Pathologic Study of 305 Lesions and Recognition of New Histologic Forms. The American Journal of Surgical Pathology, 23, 1441-1454. http://dx.doi.org/10.1097/00000478-199912000-00001

[20] Uggowitzer, M., Kugler, C., Groll, R., et al. (1998) Sonographic Evaluation of Focal Nodular Hyperplasias (FNH) of the Liver with a Transpulmonary Galactose-Based Contrast Agent (Levovist). The British Journal of Radiology, 71, 1026-1032. http://dx.doi.org/10.1259/bjr.71.850.10211062

[21] Ishak, K.G. and Rabin, L. (1975) Benign Tumors of the Liver. Medical Clinics of North America, 59, 995-1013. http://dx.doi.org/10.1016/S0025-7125(16)31998-8

\section{Submit or recommend next manuscript to SCIRP and we will provide best service for you:}

Accepting pre-submission inquiries through Email, Facebook, LinkedIn, Twitter, etc.

A wide selection of journals (inclusive of 9 subjects, more than 200 journals)

Providing 24-hour high-quality service

User-friendly online submission system

Fair and swift peer-review system

Efficient typesetting and proofreading procedure

Display of the result of downloads and visits, as well as the number of cited articles

Maximum dissemination of your research work

Submit your manuscript at: http://papersubmission.scirp.org/ 